\title{
Dam Break Flood Risk Assessment for Laiyang City
}

\author{
Li Changzhi $^{1}$, Wang Hong ${ }^{1}$,Chi Zhixue ${ }^{2}$, Yang Yongfeng ${ }^{2}$, Rao Zhengfu ${ }^{3}$ and Cope Mike ${ }^{3}$ \\ 1. China Institute of Water Resources and Hydropower Research, Beijing 100038, China \\ 2. Dept. of Water Resources, Jinan 250013, China \\ 3. Halcrow China Limited, Level 10 Millennium City 6392 Kwun Tong Road, Kowloon, Hong Kong
}

\begin{abstract}
A dam failure analysis was performed for the City of Laiyang to determine the flood inundation extents and the breach velocities of a hypothetical failure of the Muyu Reservoir Dam in Shandong Province, China. The study was carried out in four steps. First, the possible reasons of the dam failure were analyzed, and the extreme hydrological event was identified as the most critical cause. Second, a numerical simulation of the dam break flood was performed. The key factors considered in this simulation include the water level at the dam (the check flood water level), the inflow to the reservoir (the check flood hydrograph), and two typical structural scenarios (with/without-levees) along the river reach downstream of the reservoir. Third, based on flood simulations, flood hazard risk analysis was conducted and the results indicate that the peak discharge would be over $40,000 \mathrm{~m}^{3} / \mathrm{s}$ at the breachand over $22,000 \mathrm{~m}^{3} / \mathrm{s}$ near Laiyang City. As a result, most of the urban area would be flooded; the duration from the beginning of the dam break to the arrival of peak discharge at Laiyang City is less than half an hour. Finally, a plan for integrated dam break flood management was presented to mitigate the flood risk; both available structural and nonstructural measures were proposed according to the situations in the river basin. The main strategic advises include flood emergency planning, flood risk mapping, flood monitoring and early warning system construction, reservoir regulation, and flood risk public awareness.
\end{abstract}

Key words: Dam-break flood, risk assessment, laiyang city, strategy.

\section{Introduction}

As water resources are essential for our civilization, many cities were developed along rivers, usually located at the downstream of various hydraulic structures such as dikes, reservoirs, and gates. While these structures are provided many benefits, they also expose lives and properties at higher flood risks due to the potential failure of these structures [1, 2]. To protect cities from such devastating flood disasters, practicing integrated flood risk management at the river basin level becomes important, and many projects have been carried out in recent years [3-6]. The emphasises in these projects focused on the scenario analysis of dam break [7, 8], the formation of breach [9-12], and the assessment on sequences [13], life losses [14, 15], risk and emergency management measures [16-21].

Corresponding author: Li Changzhi, senior engineer, research field: water hazards management. E-mail: lichangzhi@iwhr.com.
Since 2006, a policy has been implemented in China for a large number of old reservoirs' enhancement and reinforcement for water supply and flood risk management for cities in the downstream areas. This study, taking Laiyang City and Muyu Reservoir as an example, focused on extreme flood risk assessment due to a dam failure, then discussed an integrated flood risk management strategy.

\section{Study Approach}

\subsection{Site Description}

As one of the important cities in Shandong Province, Laiyang City is located at the downstream area of the Muyu Reservoir in the mid-down reach of the Xianhe River, a branch of the Wulong River. Fig. 1 illustrates the location of the Muyu Reservoir in the Xianhe River watershed, which exhibits a long and narrow shape, with denuded low hills of the Ludong Structure. The altitude of the watershed ranges from $500 \mathrm{~m}$ in the north to $300 \mathrm{~m}$ in the south. The duration of a single 


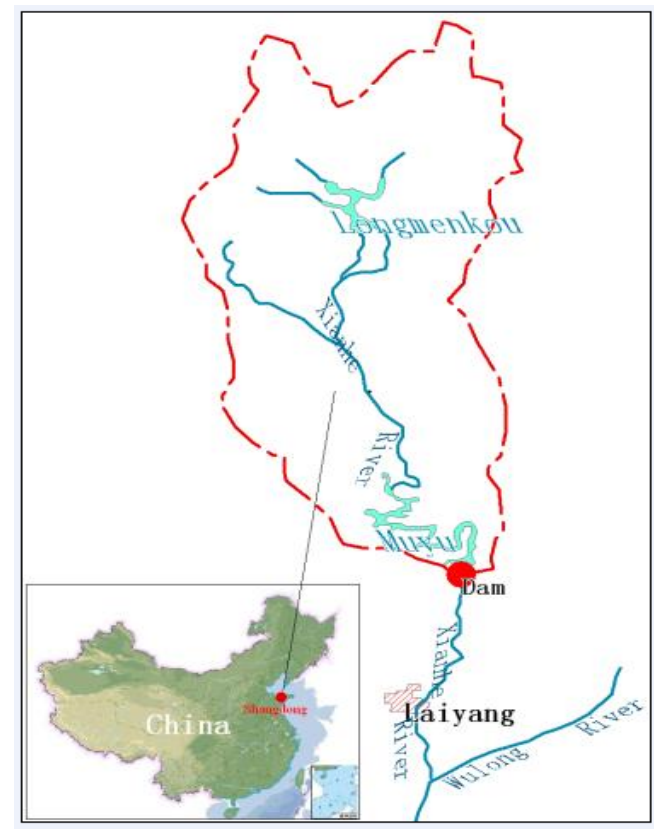

Fig. 1 Location map of the Xianhe River watershed.

flood event typically lasts 15-20 hours. The Muyu Reservoir located on the main reach of the Xianhe River. From the dam site, the river extends $42 \mathrm{~km}$ upstream in a north-eastern direction with a mean channel slope of $1.32 \%$. At the downstream of the dam site, the river passes through the east urban district of Laiyang City.

There are two major reservoirs in the watershed. The Muyu Reservoir is the primary feature; the Longmenkou Reservoir, located at the headwater area, is the secondary feature (see Fig. 1). The key hydraulic structures of the Muyu system include the dam, spillways, outlets, and monitoring facilities. The dam is a clay core earth structure, with a maximum height of $44.80 \mathrm{~m}$, a length of $310 \mathrm{~m}$, and a crest-width of $7.4 \mathrm{~m}$. The crest elevation is $90.76 \mathrm{~m}$, and the wave wall top elevation is $91.96 \mathrm{~m}$.

Laiyang City includes four districts, Chengxiang, Guliu, Longwangzhuang and Fenggezhuang, with a total population of 250,000. The Muyu Reservoir is 9 $\mathrm{km}$ northeast of Laiyang urban area. It covers an area of $455 \mathrm{~km}^{2}$ and serves as a grade II multipurpose reservoir for the city and the vicinity area providing flood prevention, irrigation, water supply, as well as power generation and agriculture usage.
Along the downstream of the Reservoir, there are also many villages and towns, with a total population of 150,000 and farmlands of 4,000 ha. In addition, two major transportation infrastructures run across the area, the Yan-Qing Highway and the Lan-Yan Railway (see Fig. 2).

\subsection{Dam Failure Flood Scenarios}

In general, dam failure disasters are induced either by eternal force or internal erosion. The documents of USACE Hydrologic Engineering Centre [22] present the factors as follows: 1) earthquake; 2) landslide; 3) extreme storm; 4) piping; 5) equipment malfunction; 6) structure damage; 7) foundation failure; and 8) sabotage. The most probable factors arising dam break in this basin flood include overtopping in extreme floods, geological disaster, dam failure in the upper reach, and terrorist attack. Geological disaster, such as earthquake, will ruin the stability and the structures of the main components of the water control project, such as dam, spillway, outlets, and then results in dam break flood. However, the river channel, levees and the city in the downstream will also suffer from the disaster, and the contributor to the heavy loss in this case is not only the dam break flood. Dam failure at the upper

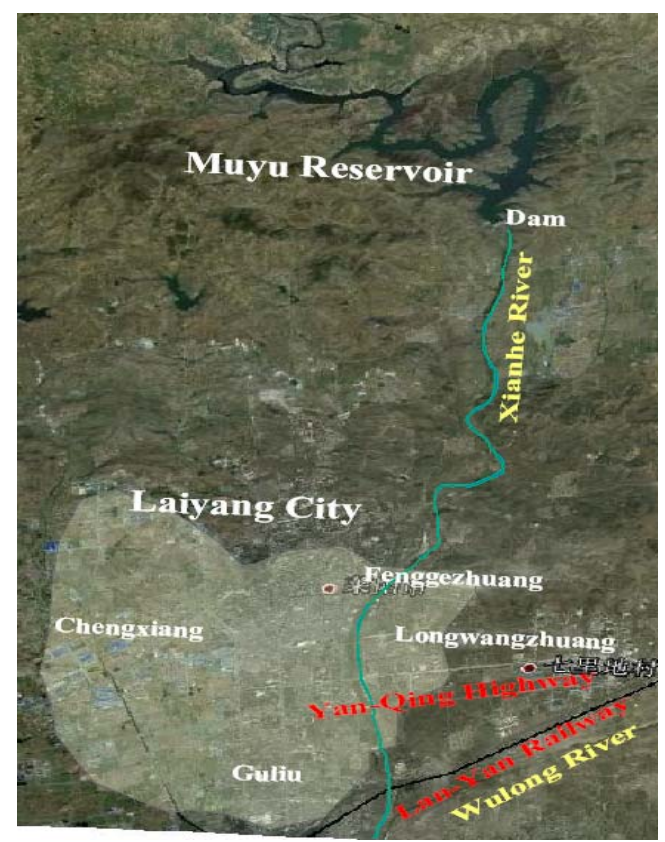

Fig. 2 Layout of Muyu Reservoir and Laiyang City. 
reach, although possible, the damage is not severe. Because there is one medium-sized reservoir, two small class-1-reservoirs and 19 small class-2-reservoirs in the upstream area of the Muyu Reservoir, with total volume capacity of $77 \mathrm{Mm}^{3}$, only that of $40 \%$ Muyu Reservoir, and the flood will run over $20 \mathrm{~km}$ in the mountainous river channel, and the energy of dam break flood from the upper reach will be significantly decreased by the very long and narrow shape of Muyu Reservoir (refer to Fig. 1). While a dam-break due to a terrorist attack is instantaneous and themost disastrous, the possibility that a reservoir like Muyu subject to terrorist attack is remote. Moreover, the dam-break caused by extreme flood events posts great uncertainty and difficult to prevent. Therefore, in this study, much attention was focused on the extreme flood events, rather than geological disaster, dam failure in the upper reach, and terrorist attack, when the dam break flood risk assessment was conducted.

In addition to above, according to the Flood Control Plan of Laiyang City (1999) [23], a proposed levee system will be constructed along both banks of the Xianhe River, with the exception of the river reach through the urban area of Laiyang in order to provide a scenic view to the public.

Based on above analysis, the following two flood scenarios for dam break in this study include: (1) overtopping failure due to an extreme flood event without dike system along the banks in the lower reaches; (2) overtopping failure due to an extreme flood event with dike system along the banks in the lower reaches. Basically, all breaks begin with a breach formation, and the breach is the opening in the dam body that leads to the break and causes the concentrated water behind the dam to routine downwards, and the study [24] indicates that the variation of dam break parameters exhibit minor impact on the water surface profile in downstream area; therefore, as a clay core earth dam, the breach mode in this study was presumed as gradual, and sensitivity analysis was performed for several key parameters.

\subsection{Dam Break Flood Simulation}

2.3.1 Dam Break Flood Modeling Theory and Tool Many tools for Dam break flood modeling, such as HEC-RAS [25], WOLF 2D [26, 27], MIKE [28], SOBEK [7], and others [29], can be found, and HEC-RAS was used in this study for its universality and usability. In this tool, unsteady flow analysis is used to conduct the flood modeling in this study. The continuity equation and momentum equation are the main scientific basis for unsteady flow analysis [25]. The continuity equation is as follow:

$$
\frac{\partial A}{\partial t}+\frac{\partial Q}{\partial s}-q_{l}=0
$$

where,

$$
\begin{aligned}
& A=\text { flow area, } \mathrm{m}^{2} ; \\
& Q=\text { volume of flow, } \mathrm{m}^{3} / \mathrm{s} ; \\
& q_{l}=\text { the lateral inflow per unit length, } \mathrm{m}^{2} / \mathrm{s} ; \\
& t=\text { time variable, } \mathrm{s} ; \\
& s=\text { spatial distance along the direction of flow, } \mathrm{m} .
\end{aligned}
$$$$
\text { And one form of the momentum equation is as }
$$
follow:

$$
\frac{\partial Q}{\partial t}+\frac{\partial Q V}{\partial s}+g A\left(\frac{\partial z}{\partial s}+S_{f}\right)=0
$$

where,

$V=$ flow velocity, $\mathrm{m} / \mathrm{s}$;

$z$ = elevation of water surface, $\mathrm{m}$;

$g=$ gravitational acceleration, $\mathrm{m} / \mathrm{s}^{2}$;

$$
S_{f}=\frac{Q|Q| n^{2}}{R^{4 / 3} A^{2}}
$$

where,

$n$ = manning's roughness coefficient;

$R=$ hydraulic radius, $\mathrm{m}$.

\subsubsection{Data Collection}

The following data, required to simulate the dam break flood, were collected.

\subsubsection{The Muyu Reservoir Data}

The key components of Muyu Reservoir consist of a clay core dam, two spillways (the main with gate, and auxiliary), two outlets (east, west) and one power station. The clay core earth dam is $44.80 \mathrm{~m}$ high, $310 \mathrm{~m}$ long, $7.4 \mathrm{~m}$ in crest-width with the crest elevation at 
$90.76 \mathrm{~m}$. The upstream face is protected by riprap, with berms built at the elevations of $81.35 \mathrm{~m}, 69.38 \mathrm{~m}$, and $55.96 \mathrm{~m}$, respectively.

The Muyu Reservoir is designed for the 100-year event, with a design pool elevation of $84.55 \mathrm{~m}$; and the 5,000-year event as the extreme-flood protection, with a flood pool elevation of $87.17 \mathrm{~m}$. The normal impounded level of the reservoir (active level) is $81.96 \mathrm{~m}$, with a storage volume of $107 \mathrm{Mm}^{3}$; the dead water level is $55.96 \mathrm{~m}$ with a dead volume of $2.1 \mathrm{Mm}^{3}$. Fig. 3 depicts the elevation-volume relationship of the Muyu Reservoir.

\subsubsection{Land Use Features}

A topographic map with a scale of $1: 20,000$ and contour interval of 2.5 meters offered the layers of the river system, reservoir, levees, roads, railways, and resident areas (refer to Fig. 2).

2.3.2.3 Data for Structural and Non-structural Measures

The geometry data of the proposed levee system was obtained from Ref. [23]. Typically, $3 \mathrm{~m}$ high levee system would be proposed along both banks of the Xianhe River.

\subsubsection{Geometric Data}

The basic geometric data consisted of cross section data and reach lengths, energy loss coefficients (friction losses, contraction and expansion losses), as well as hydraulic structure data (bridges, culverts, spillways, weirs, etc.).

There are four bridges located within the urban area of Laiyang City. Although these bridges would post certain localised impact on flood levels, they were not included in the dam-break model because the detailed bridge information was not available. Fig. 4 presents the river system and the layout of cross sections. As illustrated in Fig. 4, there were 17 cross-sections along the river reach from Muyu Dam to the river mouth.

The cross-section geometry was composed of two different sources; the in-channel cross sections were taken from Ref. [23], and the anticipated inundation areas were developed using the latest topographic map.
The Manning's coefficients for the channel and overbank areas were estimated based on the field investigation conducted in December, 2011, which gave 0.035 for the main channel and 0.045 for typical overbank areas.

The total length of the river reach is approximately $16 \mathrm{~km}$, and the distances between cross-sections are around $1 \mathrm{~km}$.

There are four narrow sections as the river passing through the urban area of Laiyang City. They are located between CS3 and CS7, near CS8, between CS11 and CS12, and between CS16 and CS17.

It is necessary to supplement surveyed cross-section data by interpolating cross-sections between the surveyed sections. Interpolated cross sections are often

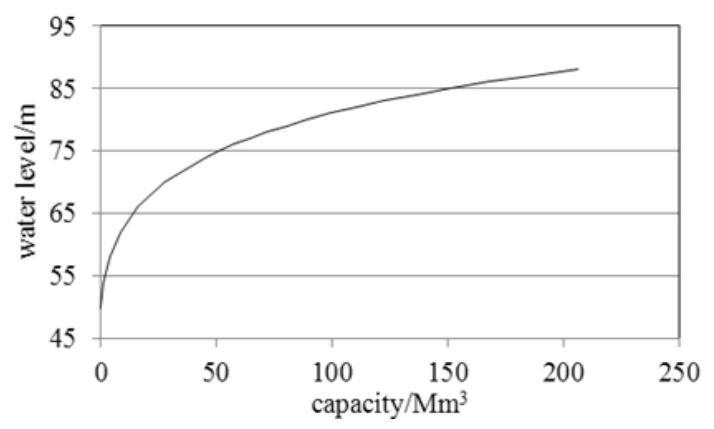

Fig. 3 Elevation-volume relationship.

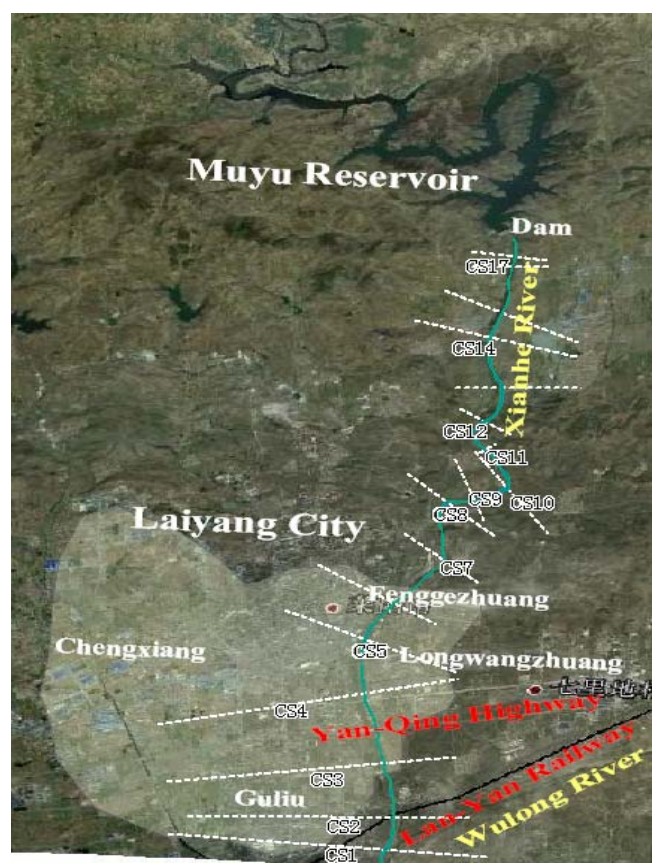

Fig. 4 River system and cross sections. 
required when the change in velocity head is too large to accurately determine the energy gradient. An adequate depiction of the change in energy gradient is necessary to accurately model friction losses as well as contraction and expansion losses. The river, after flowing through a narrow valley, passes a wide plane, then goes through a narrow saddle. In order to achieve reasonable results, cross section interpolation is necessary. The distance between two interpolated cross sections is about $250 \mathrm{~m}$.

\subsubsection{Dam Breach Mode}

Dam break flood is one of the most severe disasters for the downstream area. According to the basic information of the reservoir, the dam, and the layout of the dam, the breach information was presented in Fig. 5a. Here, the initial water surface was the check flood level of the reservoir $(87.17 \mathrm{~m})$; failure mode was overtopping; the final bottom width was $50 \mathrm{~m}$; the full formation time was about one hour. And the breach progress was assumed as following a sine wave (Fig. 5b). Special attention had been directed to the clay core earth dam for breach formation and the long strip of the Muyu Reservoir.

\subsubsection{Rating Curve Analysis}

Fig. 6 presents the rating curves at cross sections CS17, CS7, CS3 and CS1. The cross sections CS17 and CS1 represent, respectively, the upper and lower boundary of the river reach; the CS7 and CS3 located at the urban area. As demonstrated in Fig. 6, all curves exhibit a looping shape, and the rating curves from all other cross sections possess the similar trend.Therefore, the simulation results of stage and discharge are reasonable.

\section{Results and Discussions}

\subsection{Flood Hazard Analysis}

The hazard information on the dam break flood is provided in Figs. 7 and 8 and Table 1. Fig. 7 indicates the water surface profiles of dam break flood simulation in two scenarios, Fig. 8 illustrates the water stage process at CS7, and Table 1 lists numeric information. River reach from CS7 to CS3 runs through the urban area (refer to Fig. 4). In Table $1, Q_{1}$ and $Q_{2}$ are the peak discharges at each cross section for scenario 1 and scenario 2, respectively, while $W S_{1}$ and $W S_{2}$ are the maximum water surface at each cross section in the two scenarios, respectively. $H_{a}$ stands for the elevation of levee top and $H_{b}$ for the elevation of river channel bed.

Figs. 7 and 8 and Table 1 show the following results: (1) Table 1 indicates that the peak discharges at each cross section in both scenarios are in close proximity to each other. And the peak discharges were over $43,000 \mathrm{~m}^{3} / \mathrm{s}$ at the breach and over $22,000 \mathrm{~m}^{3} / \mathrm{s}$ at the conjunction between the Xianhe River and the Wulong River.

According to Ref. [23], the flow capacity at the river reach near Laiyang City is only about $800 \mathrm{~m}^{3} / \mathrm{s}$ (once in 50 years), much less than the peak discharge of dam

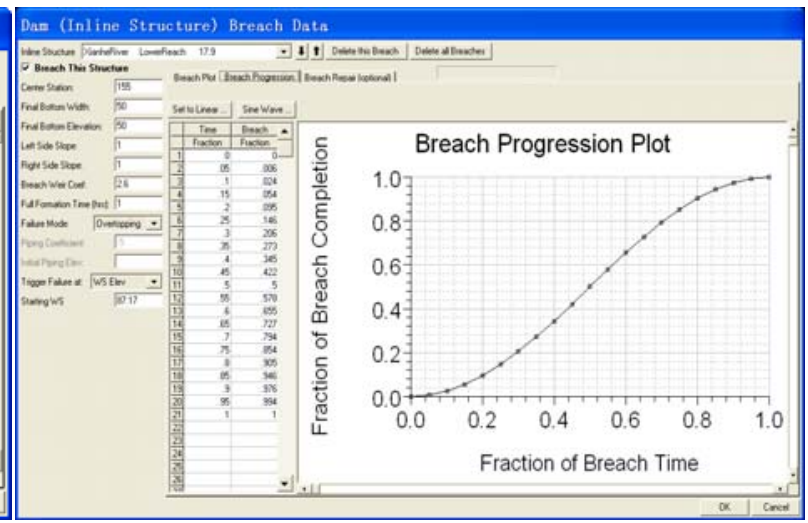

(b) Breach progress for dam break flood

Fig. 5 Breach configurations for dam break flood. 

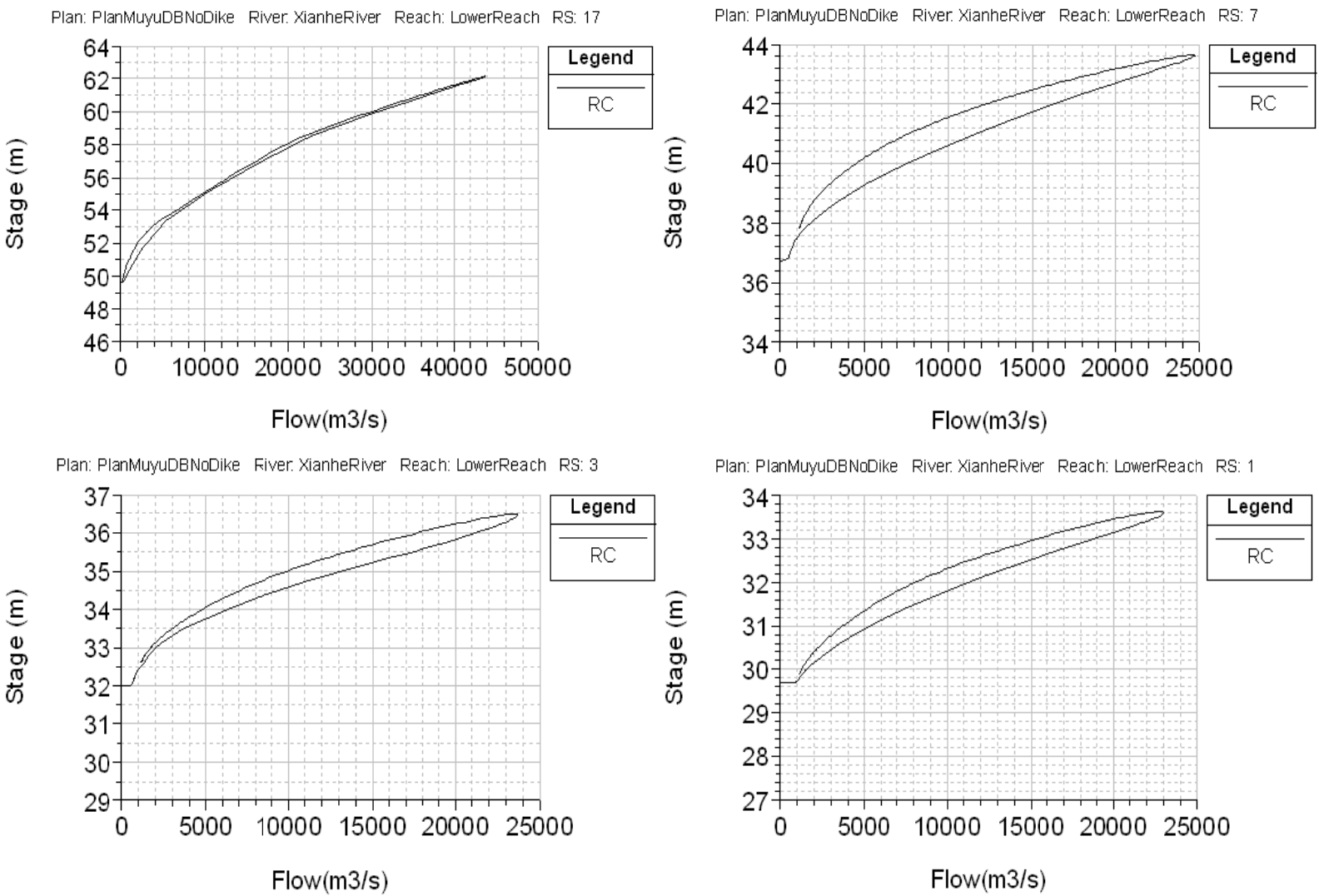

Fig. 6 Rating curves at RS17, RS7, RS3 and RS1.

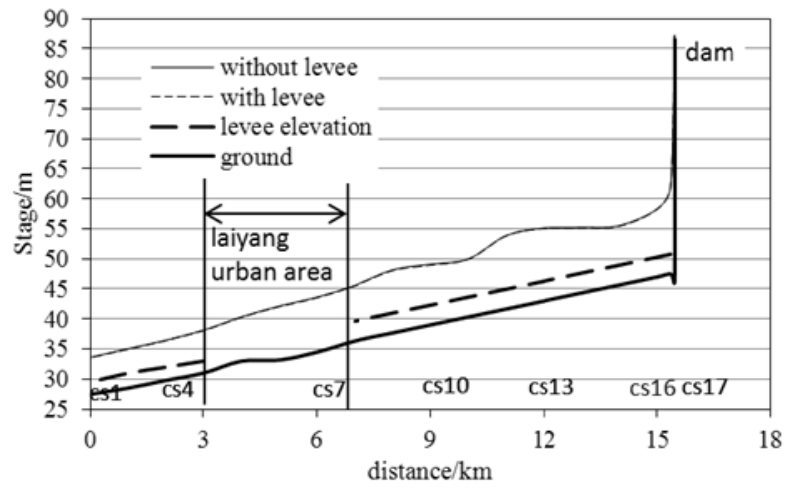

Fig. 7 Water surface profiles for dam break flood.

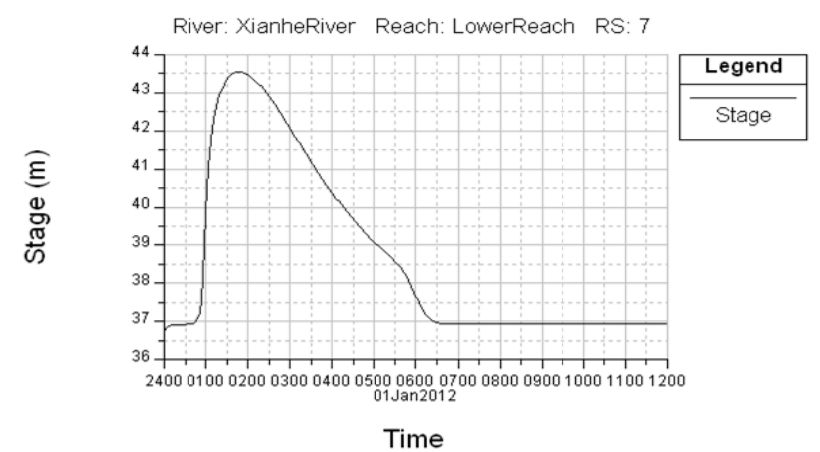

Fig. 8 Water stage process at CS7 (closing to Laiyang City).

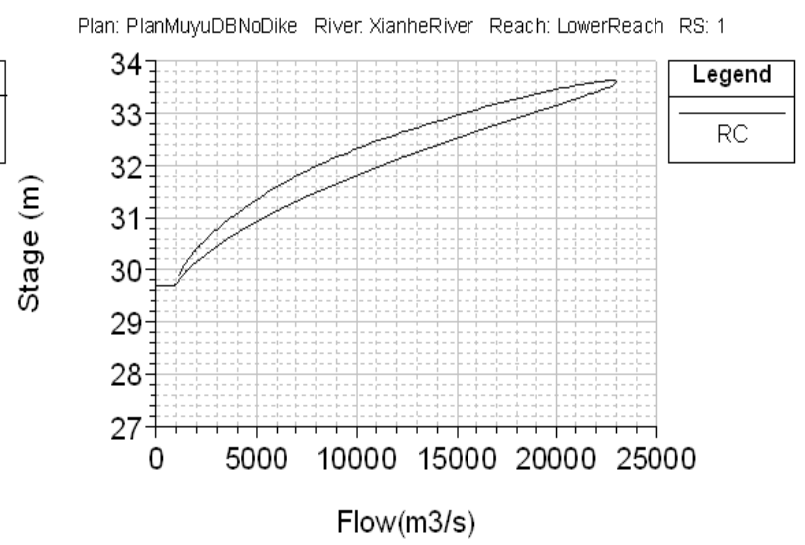

break flood.

(2) Similar to the trend of peak discharge, the maximum water stages at each cross section in both scenarios are also quite closed to each other, and the maximum difference is only $0.15 \mathrm{~m}$. Fig. 6 indicates that the dam-break wave elevation at each cross-section is much higher than that at top of the levee. The maximum water stages are over $40 \mathrm{~m}$ at CS5 and $43 \mathrm{~m}$ at CS7, over the bank crests about 5-7 m, which means heavy flooding will occur in the urban area.

(3) It takes short time for the peak discharge of dam break flood to arrive in the river reach near Laiyang City. According to the presumed breach mode, the discharge at the dam reaches its peak less than 30 minutes. And only about 20 minutes the dam break flood would be over the bank at CS7, and it takes less than 30 minutes that the flood water stage rises from the elevation of the bank (37.40 m) to the maximum stage. All of above analysis indicates that the available 
Table 1 Main results of dam break flood simulation.

\begin{tabular}{lllllllllll}
\hline $\mathrm{C}$ & $\begin{array}{l}\text { Distance } \\
(\mathrm{km})\end{array}$ & \multicolumn{2}{c}{ Max. discharge $\left(\mathrm{m}^{3} / \mathrm{s}\right)$} & \multicolumn{2}{c}{ Max. water surface $(\mathrm{m})$} & $\mathrm{H}_{\mathrm{a}}(\mathrm{m})$ & $\mathrm{H}_{\mathrm{b}}(\mathrm{m})$ & \multicolumn{3}{c}{ Difference $(\mathrm{m})$} \\
\cline { 2 - 10 } & $Q_{1}$ & $Q_{2}$ & $W S_{1}$ & $W S_{2}$ & & & $W S_{1}-H_{a}$ & $W S_{2}-H_{a}$ & $W S_{1}-W S_{2}$ \\
\hline 17 & 15.35 & 43,706 & 43,705 & 62.14 & 62.18 & 50.78 & 47.48 & 11.36 & 11.40 & -0.04 \\
16 & 15.00 & 43,548 & 43,629 & 58.35 & 58.31 & 50.31 & 47.01 & 8.04 & 8.00 & 0.04 \\
15 & 14.00 & 26,369 & 25,605 & 55.54 & 55.45 & 48.98 & 45.68 & 6.56 & 6.47 & 0.09 \\
14 & 13.00 & 25,726 & 24,976 & 55.26 & 55.19 & 47.65 & 44.35 & 7.61 & 7.54 & 0.07 \\
13 & 12.00 & 25,630 & 24,893 & 55.13 & 55.07 & 46.31 & 43.01 & 8.82 & 8.76 & 0.06 \\
12 & 11.00 & 25,567 & 24,838 & 53.90 & 53.88 & 44.98 & 41.68 & 8.92 & 8.90 & 0.02 \\
11 & 10.00 & 25,538 & 24,816 & 49.99 & 49.97 & 43.65 & 40.35 & 6.34 & 6.32 & 0.02 \\
10 & 9.00 & 25,010 & 24,200 & 49.12 & 48.97 & 42.31 & 39.01 & 6.81 & 6.66 & 0.15 \\
9 & 8.00 & 24,881 & 24,101 & 48.16 & 48.06 & 40.98 & 37.68 & 7.18 & 7.08 & 0.10 \\
8 & 7.00 & 24,832 & 24,061 & 45.59 & 45.53 & 39.65 & 36.35 & 5.94 & 5.88 & 0.06 \\
7 & 6.00 & 24,637 & 23,852 & 43.64 & 43.55 & $37.40^{*}$ & 34.50 & 6.24 & 6.15 & 0.09 \\
6 & 5.00 & 24,475 & 23,718 & 42.15 & 42.07 & $36.30^{*}$ & 33.18 & 5.85 & 5.77 & 0.08 \\
5 & 4.00 & 24,394 & 23,606 & 40.35 & 40.29 & $34.78 *$ & 33.00 & 5.57 & 5.51 & 0.06 \\
4 & 3.00 & 24,090 & 23,347 & 38.13 & 38.07 & 33.00 & 31.00 & 5.13 & 5.07 & 0.06 \\
3 & 2.00 & 23,460 & 22,679 & 36.49 & 36.42 & 32.00 & 29.80 & 4.49 & 4.42 & 0.07 \\
2 & 1.00 & 23,175 & 22,389 & 35.07 & 35.00 & 31.00 & 28.52 & 4.07 & 4.00 & 0.07 \\
1 & 0.00 & 22,716 & 21,951 & 33.63 & 33.56 & 29.50 & 27.48 & 4.13 & 4.06 & 0.07 \\
\hline
\end{tabular}

The star sign (*) stands for the elevation of the bank crest closing to the river channel.

warning time is very limited!

(4) The simulating results illustrate that the flow velocities in the river reach near Laiyang City reach up to $4-5 \mathrm{~m} / \mathrm{s}$, a very dangerous velocity to lives and properties.

Fig. 9 presents the inundation area in case of a dam failure; it is clear that the urban area suffers heavily from the catastrophic flood.

Moreover, it should be emphasized that the available data on bridge hydraulics within the urban area was limited and omitted when flood modelling was performed. Obviously, flooding in large scale floods would become more serious than that described and illustrated above if these bridges were fully taken into consideration, as these bridges have potential restricting waterway.

\subsection{Other Considerations}

\subsubsection{The Impact from Reservoir Inflow}

Fig. 10 is a plot of the 5000-year inflow hydrograph for the Muyu Reservoir, obtained using comprehensive inflow unit hydrography method.

It reveals a peak inflow of $5,320 \mathrm{~m}^{3} / \mathrm{s}$, approximately $1 / 8$ of the dam breach out flow of $43,700 \mathrm{~m}^{3} / \mathrm{s}$. As stated above, the surface length of the reservoir is $42 \mathrm{~km}$ from the head of the reservoir to the dam location; and the river channel between the Muyu Dam and the Longmenkou Dam is narrow and meandering. The distance, from the dam to Layang, is

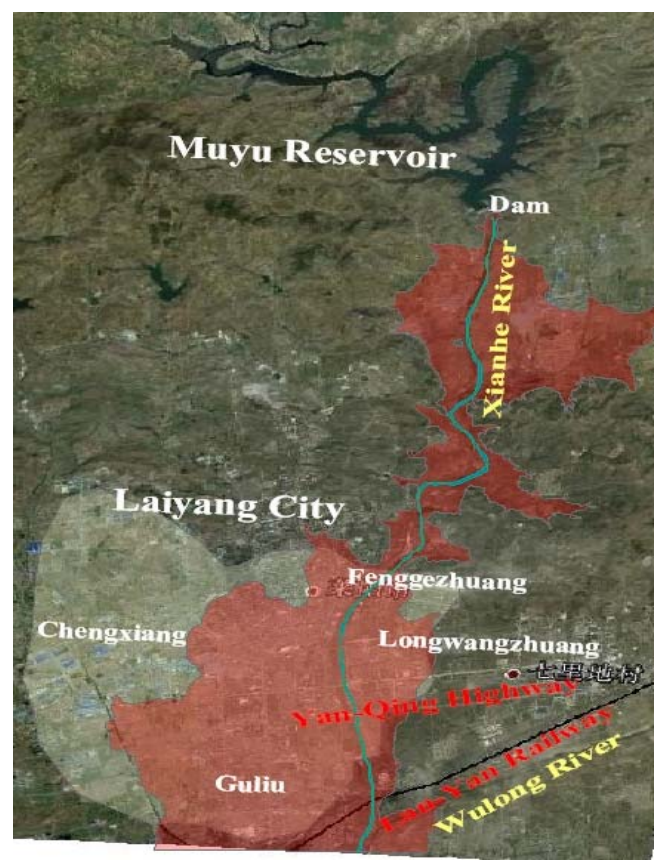

Fig. 9 Inundation map of dam break flood. 


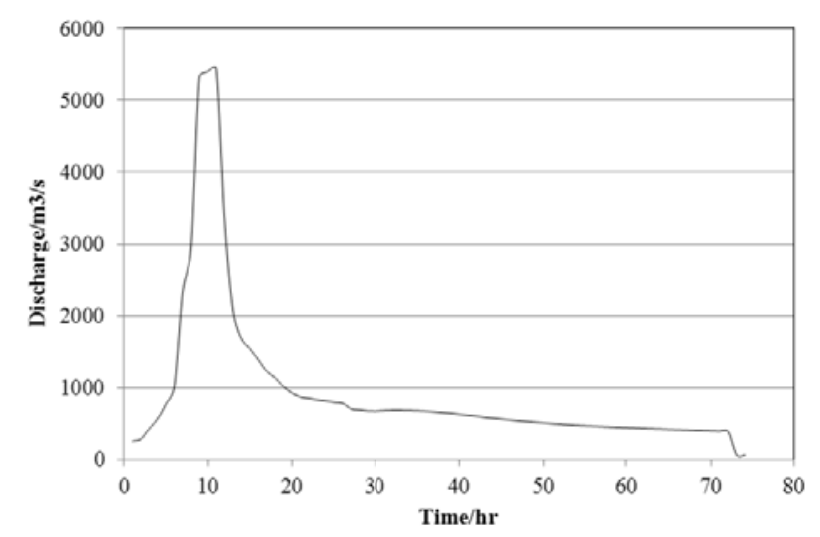

Fig. 10 5000-year inflow hydrograph for Muyu Reservoir.

about $9 \mathrm{~km}$. Considering the significant length of the reservoir and the short distance from the dam to the city, the impact of the inflow to the dam failure results is negligible.

\subsubsection{Sensitivity Analysis}

The results of dam break studies are largely depend on the set of assumptions made to the parameters. Therefore, sensitivity analysis was performed in order to estimate the impact of varying the model parameters to the model results. These parameters include full formation time, breach depth, breach width, and breach side slope. Based on simulated peak breach discharge, the breach sensitivity analysis for Muyu Dam is summarized in Table 2, and Fig. 11 presents the sensitivity analysis comparison at CS17 and CS7, which represent the breach location, entrance of the city, respectively.

Table 2 Summary of sensitivity analysis results.

\begin{tabular}{|c|c|c|c|c|}
\hline Cross section & & & CS17 & CS7 \\
\hline \multirow{2}{*}{ Without adjust } & & W.S. Elev (m) & 62.14 & 43.64 \\
\hline & & VelChnl (m/s) & 17.35 & 4.85 \\
\hline \multirow{8}{*}{ Adjusted full formulation time } & \multirow{2}{*}{$+20 \%$} & W.S. Elev (m) & 62.09 & 43.63 \\
\hline & & VelChnl (m/s) & 17.28 & 4.84 \\
\hline & \multirow{2}{*}{$-20 \%$} & W.S. Elev (m) & 62.27 & 43.64 \\
\hline & & VelChnl (m/s) & 17.52 & 4.85 \\
\hline & \multirow{2}{*}{$+50 \%$} & W.S. Elev (m) & 61.95 & 43.62 \\
\hline & & VelChnl (m/s) & 17.06 & 4.84 \\
\hline & \multirow{2}{*}{$-50 \%$} & W.S. Elev (m) & 62.37 & 43.65 \\
\hline & & VelChnl (m/s) & 17.74 & 4.85 \\
\hline \multirow{8}{*}{ Adjusted breach width } & \multirow{2}{*}{$+20 \%$} & W.S. Elev (m) & 63.02 & 43.87 \\
\hline & & VelChnl (m/s) & 18.6 & 5.04 \\
\hline & \multirow{2}{*}{$-20 \%$} & W.S. Elev (m) & 61.3 & 43.38 \\
\hline & & VelChnl (m/s) & 16.11 & 4.64 \\
\hline & \multirow{2}{*}{$+50 \%$} & W.S. Elev (m) & 64.22 & 44.16 \\
\hline & & VelChnl (m/s) & 20.3 & 5.31 \\
\hline & \multirow{2}{*}{$-50 \%$} & W.S. Elev (m) & 59.86 & 42.9 \\
\hline & & VelChnl (m/s) & 14.06 & 4.28 \\
\hline \multirow{8}{*}{ Adjusted side slope } & \multirow{2}{*}{$+20 \%$} & W.S. Elev (m) & 61.73 & 43.53 \\
\hline & & VelChnl (m/s) & 16.73 & 4.76 \\
\hline & \multirow{2}{*}{$-20 \%$} & W.S. Elev (m) & 62.62 & 43.74 \\
\hline & & VelChnl (m/s) & 18.04 & 4.93 \\
\hline & \multirow{2}{*}{$+50 \%$} & W.S. Elev (m) & 61.03 & 43.36 \\
\hline & & W.S. Elev (m) & 15.73 & 4.62 \\
\hline & \multirow{2}{*}{$-50 \%$} & $\operatorname{VelChnl}(\mathrm{m} / \mathrm{s})$ & 63.27 & 43.88 \\
\hline & & W.S. Elev (m) & 18.95 & 5.06 \\
\hline \multirow{4}{*}{ Adjusted breach depth } & \multirow{2}{*}{$-20 \%$} & VelChnl (m/s) & 59.62 & 42.74 \\
\hline & & W.S. Elev (m) & 13.72 & 4.17 \\
\hline & \multirow{2}{*}{$-30 \%$} & VelChnl (m/s) & 58.35 & 42.23 \\
\hline & & W.S. Elev (m) & 11.97 & 3.82 \\
\hline
\end{tabular}

W.S. Elev = water surface elevation; VelChnl = velocity of flow in river channel. 


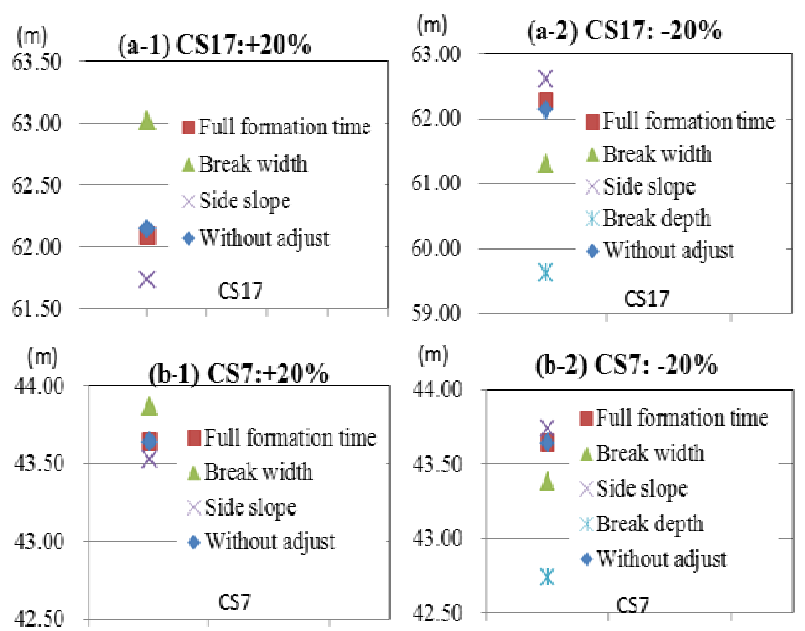

Fig. 11 Sensitivity analysis comparison at CS17 and CS7.

Fig. 11 presents the changes of water surface at CS17 and CS7 with variations of full formation time, breach depth, breach width, and breach side slope. As indicated in Table 2 and Fig. 11, all four breach parameters affect the model results. The breach depth appeared to be the most sensitive parameter; the deeper the beach depth is, the higher the water elevations and mean velocities are. The breach width is the second sensitive parameter; the longer breach width produced a higher water elevation and mean velocity. The variation of the breach side slope had a less significant impact on the model results; and the influence of the full formation time is minimum comparing to other three parameters.

Table 2 and Fig. 11 also demonstrate that the impact of the parameter variation diminishes along the river. The impact of the sensitivity analysis is significantly higher at the dam location and diminishes towards downstream.

\subsection{Integrated Flood Management Analysis}

The analyses of dam break flood demonstrate that a dam break event would be devastating for the downstream area. Because of the relatively short distance from the dam, Laiyang would be heavily flooded in an hour or less, in case of a dam failure. However, FRM (flood risk management) in the Xianhe river basin is largely depend on Muyu Reservoir and other structural measures, such as river training and the raising of dykes. To mitigate the risk posted by a dam failure, it will be vital to maintain proper dam operation, provide early warning and have a highly effective and efficient evacuation plan to higher ground above predicted flood levels. Therefore, a future FRM strategy for Laiyang should include a more balanced set of responses. A few recommendations are discussed below.

(1) Maintaining an appropriate reservoir operation. The dam operation is designed that the maximum discharge does not exceed safe discharge threshold and that the maximum reservoir level does not exceed the specified flood level (or flood checking level). Plans to ensure reservoir safety include a co-ordinated approach between maintaining dam safety and the provision of flood safety downstream. This is achieved through an understanding of the relationship between reservoir operation and downstream flood risk as well as an understanding of when to implement flood prevention measures.

(2) Providing early warning and a highly effective and efficient evacuation plan. The analyses indicate that the levees make almost no difference in flooding in Laiyang City in case of dam break flood of Muyu Reservoir. However, it is always possible for a flood event to occur that will exceed the available safe flood storage volume within the reservoir, thus needing plans to mitigate flood damage and to prevent the loss of life downstream. The flood alerts should be issued to the downstream area as soon as the flood warning water level thresholds in the reservoir are reached; the authorities need to remain vigilant and prepared to instigate their flood preparedness plan, with timely evacuation of residents from flood risk zones to places of safety as and when appropriate. Moreover, a highly effective and efficient evacuation plan is practically needed, and the evacuation routes and centres require careful planning, as well as access routes for emergency services and flood operations.

(3) Developing integrated flood management plan. 
The key responses of an integrated flood management plan appropriate to the Xianhe River basin can be summarised under the Hazard-Exposure-Vulnerability model.

First, the "Hazard" reduction options are where a higher level plan across the full river basin has real potential to provide strategic solutions that result in much greater efficiencies and effectiveness in flood risk reduction. The available options include, (a) the management on dams and reservoirs, as well as diversion channels, (b) controlling the sources, such as increasing infiltration, storage within the drainage system or on surface features, and (c) the management land use, such as regulations and practices for infrastructure and building drainage, and appropriate landscape planning.

Second, the options for reducing "Exposure" comprise, (a) structural measures (such as dykes, river training works, river bank raising and raising of railways, roads and other infrastructure), (b) individual property protection (flood proofing and flood resilience), (c) land use control and regulation within floodplains, and (d) flood forecasting, flood warning, emergency planning and evacuation.

Last, the options for reducing "Vulnerability" cover, (a) improving the physical living environment by improving infrastructure and providing better occupational opportunities, (b) enhancing social support systems, providing skills, training, education and awareness, and facilitating equal opportunities; and (c) facilitating greater self-organisation and building awareness to create a self-reliant culture.

\section{Conclusions}

As the City of Laiyang growing rapidly in recent years, the integrated flood management becomes important. This study analysed the flood risk due to the dam break of the Muyu Reservoir. The study focused mainly on the risk assessment of dam-break flood of the Muyu Reservoir to Laiyang City.

The analysis was performed based on the available data that include: (1) the causes for possible dam-break flood's occurrence, (2) the Muyu Reservoir, (3) the land use features, (4) structural and non-structural measures, (5) the geometric data, and (6) the dam break mode. Two typical scenarios of structural measures (with levee and without levees along the river banks in downstream reach) were considered to conduct the dam break flood simulation.

The results indicate: (1) the peak breach discharge would be over $40,000 \mathrm{~m}^{3} / \mathrm{s}$ at Laiyang City; (2) the duration time from the beginning of dam failure to the arrival of peak discharge at Laiyang City is less than 30 minutes; (3) most of the urban area would be severely flooded; and (4) the average flow velocities of flood in the river reach near Laiyang City would reach up to $4-5 \mathrm{~m} / \mathrm{s}$.

The hazard degrees of dam break flood in the two scenarios of structural measures are similar. It indicates that common structural measures would not produce significant difference in such extreme event like dam break flood. Instead, sufficient attention should be directed to non-structural measures, such as reservoir regulation, early warning, evacuation plan, flood risk public awareness, and practicing integrated flood management in Xiahe River basin.

\section{Acknowledgements}

The study was sponsored by the China's Project "National Flash Flood Hazard Prevention and Control" and the Technical Assistance Project of Asian Development Bank "Effective Reservoir Utilization for Integrated Water Resources Management” (ADB TA-7658 PRC).

\section{References}

[1] Lei, L., and Lu, Y. 2003. "Reservoir and Dam Safety Management Practices and Challenges Faced by China." China Water ResourcesA 11 (5): 59-62. (in Chinese)

[2] Liang, R., and Li, L. 2014. "Review on Pros and Cons of Dam Construction.” Technology Innovation and Application 26: 198. (in Chinese)

[3] NHRI (Nanjing Hydraulic Research Institute), IWHR (China Institute of Water Resources and Hydropower), 
Changjiang Institute of Survey, Planning, Design and Research, Hohai University. 2010. Study on Key Technologies for Reservoir and Dam Safety Guarantee and Their Application. Project report. (in Chinese)

[4] GHD, IWHR. 2005. National Flood Management Strategy Study. ADB final report.

[5] Samuels, P. 2009. Volume 1: Advancement in Knowledge and Understanding. Volume 2: Overview of the FloodSite Pilots. Floodsite final report.

[6] de Almeida, A. B. 2002. Dam-Break Flood Risk Management. An integrated projectfinal report.

[7] Tang,C. 2012. "2-D Flash Flood Simulation of the Tangjiashan Landslide Dam induced by the 2008 Wenchuan Earthquake.” Master thesis, Twente University.

[8] David, S. B., Loren, R. A., and Joseph, B. E. 1999. “Alamo Dam Demonstration Risk Assessment.” Presented at the Australian Committee on Large Dams Annual Meeting, Jindabyne, New South Wales, Australia.

[9] Ehsan, S. 2009. Evaluation of Life Safety Risks Related to Severe Flooding. Germany: Universität Stuttgart.

[10] Wurbs, R. A. 1987. "Dam-Breach Flood Wave Models.” Journal of Hydraulic Engineering 113: 29-46.

[11] Wahl, T. L., 2004. "Uncertainty of Predictions of Embankment Dam Breach Parameters.” Journal of Hydraulic Engineering 130 (5): 389-97.

[12] Froehlich, D. 2008. "Embankment Dam Breach Parameters and Their Uncertainties." Journal of Hydraulic Engineering 121 (1): 90-7.

[13] Margo, D. A., Hunter, J. W., and Needham, J. T. 2009. "Dam Failure Analysis and Consequence Estimation." In Proceedings of the US Society on Dams 2009 Annual Lecture, 1181-90.

[14] McClelland, D. M., and Bowles, D. S. 2002. Estimating Life Loss for Dam Safety Risk Assessment-A Review and New Approach. Alexandria, VA: IWR REPORT 02-R-3, U.S. Army Corps of Engineers.

[15] Aboelata, M. A., and Bowles, D. S. 2005. LIFE Sim: A Model for Estimating Dam Failure Life Loss. Report to Institute for Water Resources, US Army Corps of Engineers and Australian National Committee on Large Dams by Institute for Dam Safety Risk Management, Utah State University, Logan, Utah.

[16] Watson, D. J. 1998. "Business Risk Assessment of Dams-An Australian (Victorian) Experience.” Presented at the USCOLD 1998 Annual Lecture, Buffalo, New York.

[17] Almeida, A. B. 1997. "Dam-Break Flood Risk and Safety Management at Downstream Valleys: A Portuguese Integrated Research Project.” In Proceedings of the 19th
ICOLD Congress, 331-47.

[18] David, S. B., Loren, R. A., and Terry, F. G. 1998. "The Practice of Dam Safety Risk Assessment and Management: Its Roots, Its Branches, and Its Fruit.” Presented at the Eighteenth Annual USCOLD Lecture Series, Buffalo, New York.

[19] Almeida, A. B., Franco, A. B., Ramos, C. M., Santos, M. A., Viseu, T., and e Silva, D. 2000. "Dam-Valley Risk Management. First Results of a Case Study in Portugal: Arade Valley." In Proceedings of the 20th ICOLD Congress, 149-69.

[20] Saqib, E., and Silke, W. 2013. "Estimation of Possible Flooding Risks for Enhancement in Flood Resilience in River Valleys.” Journal of River Engineering, 1 (1).

[21] Gebregiorgis, A., and Hossain, F. 2012. "Hydrological Risk Assessment of Old Dams: Case Study on Wilson Dam of Tennessee River Basin.” Journal of Hydrologic Engineering 17 (1): 201-12.

[22] U. S. Army Corps of Engineers. 1997. Engineering and Design-Hydrologic Engineering Requirements for Reservoirs. Australian: Military Bookshop.

[23] Water Resources Authority of Laiyang and the Laiyang. 1999. The Flood Control Plan of Laiyang City (1999). Laiyang, Shangdong: Water Resources Authority of Laiyang and the Laiyang. (in Chinese)

[24] Xiong, Y. 2011. “A Dam Break Analysis Using HEC-RAS.” Journal of Water Resource and Protection 3: 370-9.

[25] US Army Corps of Engineers. 2008. HEC-RAS River Analysis System, Hydraulic Reference Manual (Version 4.0). Report to hydraulic engineering centre (CPD-69).

[26] Dewals, B., Archambeau, P., Erpicum, S., and Mouzelard, T. 2002. "Dam-Break Hazard Mitigation with Geomorphic Flow Computation, Using WOLF 2D Hydrodynamic Software.” In Risk Analysis III, edited by Brebbia, C. A. Billerica: WIT Press.

[27] Dewals, B. J., Erpicum, S., Archambeau, P., Archambeau, P., and Pirotton, M. 2006. "Numerical Tools for Dam Break Risk Assessment: Validation and Application to a Large Complex of Dams.” In Improvements in Reservoir Construction, Operation and Maintenance, edited by British Dam Society. London: Thomas Telford Ltd.

[28] Saqib, E., and Walter, M. 2014. "Dam Break Modeling for Large Earth and Rock-fill Dams.” Journal of River Engineering 2 (6).

[29] Seker, D. Z., Kabdasli, S., and Rudvan, B. 2003. "Risk Assessment of a Dam-Break Using GIS Technology.” Water Science \& Technology 48 (10): 89-95. 